\section{Incorporating Culture into Listening Comprehension Through Presentation of Movies}

\section{Kusumarasdyati}

Universitas Negeri Surabaya

\begin{abstract}
The use of movie videos as an instructional aid in the teaching of English as a foreign language (EFL) should be encouraged due to various pedagogical benefits. This article attempts to suggest a technique of utilizing movies in English listening classes in order to improve the aural perception skills of the learners. It comprises three stages: previewing, viewing and postviewing. In the previewing stage, learners read a brief description of the theme of the movies to activate their prior knowledge, guess the meaning of certain keywords presented in sentential contexts, or familiarize themselves with the main characters. Next, the learners view the movies - either with or without any subtitles-and while doing so they are supposed to answer several questions in written form. Finally, the learners are engaged into a postviewing activity in the form of contrasting cultures reflected in the movies. This technique of teaching listening has proved to be effective in developing listening skills in a foreign language and sensitizing them to the target culture, which is an inseparable aspect of language learning.
\end{abstract}

Key words: listening comprehension, vocabulary, culture, films

It has been widely accepted that learning a foreign language can hardly be separated from learning the culture where this language is originally spoken. This view leads educators to develop an integrated model of language and culture (Herron et al, 2002). The present paper concerns with such an attempt to integrate language and culture in listening classes. It aims to explicate a teaching technique that incorporates these two in listening instructions where students learn English as a foreign language at tertiary education insti- tutions.

It is essential, however, that a review of the concepts involved in this technique - culture, language, and listening comprehension-precede the detailed explication of the technique itself. Consequently, this paper will be divided into three sections. The first section will briefly examine the interlocking nature of language and culture as it relates to EFL, then in the second one the processes that occur during aural comprehension of EFL will be reviewed. Finally, the teaching technique will be presented in details.

\section{LANGUAGE AND CULTURE}

To date culture has been defined as various different-although somewhat related - concepts, ranging from a group of people who share the same background (Matikainen and Duffy, 2000) to the way of life of a society (Straub, 1999). As a matter of fact, Kroeber and Kluckhohn (1954, as cited by Lessard-Clouston, 1997) obtained more than three hundred definitions of culture in their investigation. This confirms the notoriously-hard-to-define nature of the term 'culture', as asserted by Byram and Grundy (2002). However, it might be appropriate and practical to consider culture in both its narrow and broader senses as the dyad of little "c" culture and big " $\mathrm{C}$ " culture. The little "c" culture refers to the aspects of lifestyle or patterns of daily living, while the big " $\mathrm{C}$ " culture represents a civilization's accomplishments in literature and the fine arts, its social institutions, its history, geography, and political system (Herron et al, 2002).

Pryor (2004), who argues that culture lies at the heart of curriculum, views culture as learned patterns of values, beliefs, perceptions and behaviors which are shared by groups of people but may be practiced differently by the members in a particular situation. She further states that these cultural patterns can be observed in the language they use, in addition to organization, customs and material products. It is apparent, then, that language is value-laden; therefore, EFL learners definitely still grasp the values that exist in the target culture even if the culture is not taught explicitly in the language class (Lessard-Clouston, 1997). On this ground it is quite reasonable that Herron et al (2002) claim culture becomes the core of foreign language instruction. 
Apparently culture plays a vital role in EFL learning; therefore, it seems to be a wise suggestion to integrate it into language instruction, regardless of the language skills (listening, speaking, reading, and writing) to be taught. As the present paper deals mainly with listening, this particular language skill will be reviewed briefly in the next section, before the integration of culture and listening is discussed

\section{LISTENING COMPREHENSION}

Formerly thought of as a passive language skill, listening was often assigned less emphasis in EFL classes than the active skill, speaking (Herschenhorn, 1979). The label of passive language skill, however, is actually a misnomer as listening requires active processing in the learners' mind despite the superficially silent activities of perceiving oral stimulus. When receiving such stimulus and then attempting to make sense of it, the learners interactively perform two types of cognitive processing, namely bottom-up (data-driven) and top-down (conceptually-driven).

The bottom-up processing involves constructing meaning from the smallest unit of the spoken language to the largest one in a linear mode (Nunan, 1998). Thus, the learners make an effort to understand a spoken discourse by decoding a number of sounds to form words. Next, a nexus of words are linked to form phrases, which make up sentences. These sentences build a complete text, the meaning of which is then constructed by the listeners. In addition to the grammatical relationships, such suprasegmental phonemes as stress, rhythm and intonation also substantially contribute to this data-driven processing (van Duzer, 1997). Learners can be trained to perform this processing, for instance, by activities that require them to discriminate two sounds or distinguish rising and falling intonations.

The top-down processing, on the other hand, refers to interpreting meaning as intended by the speakers by means of schemata or structures of knowledge in the mind (Nunan, 1998). This view emphasizes the prominence of background knowledge already possessed by the learners in making sense of the information they hear. In the aural perception, the prior knowl edge may facilitate their attempt to grasp the incoming information by relating the familiar with the new one, and significant lack of such knowledge can hamper their efforts to comprehend a particular utterance. It is, therefore, essential that learners are accustomed to performing this processing, usually by extracting the gist of the exchange they listen to.

Thus, it is justified that listening is not a passive language skill. Contrary to the misleading popular belief, comprehension through auditory channel requires some cognitive processes that interact actively in simultaneous manner. To aid the learners in performing these processes better, various materials should be carefully selected to ensure a conducive atmosphere of learning. Creating such an atmosphere can be easily conducted by selecting commercially available films in video format and employing them as listening materials in the language lab.

\section{PRESENTATION OF MOVIES IN LISTENING CLASS}

Movie videos should not be regarded as merely a peripheral 'extra' in a listening class; on the contrary, they can function as the core content and become an integral part of the curriculum (Sommer, 2001). Appropriate, creative exploitation of these movies can reveal their potentials in fostering the acquisition of listening skills (Eken, 2003); therefore, their use as instructional materials in listening lessons should be encouraged due to at least four pedagogical values.

The first benefit relates to motivation: films about issues that draw the learners' interest can positively affect their motivation to learn (Stempleski, 1992; Allan, 1985; Lonergan, 1984). My experience of teaching the university students proved this to be true. Every time I dimmed the lights in the language lab at the beginning of the listening lessons, the students immediately realized that a movie video was about to be played and they always demonstrated enthusiasm, which would not diminish even after the movie ended. Second, the movies assist the learners' comprehension by enabling them to listen to exchanges and see such visual supports as facial expressions and gestures simultaneously (Allan, 1985; Sheerin, 1982), which may boost their insights into the topic of the conversations. In real life, unless they are speaking on the telephone or listening to the radio, such visual supports are virtually present to accompany the verbal exchanges, so the existence of facial expressions and gestures in the movies can simulate the dialogues in real situations. In addition to the visual supports the films also provide exposures to the language uttered in authentic settings (Stempleski, 1992; Telatnik and Kruse, 1982). This third benefit, i.e. authentic language, is extremely valuable to assist the students in preparing for the participation 
in the real conversations because the exchanges in the movies are very similar to the ones in real life in terms the rate of delivery, the choice of words and the tendency of truncations (such as elliptical structures and contractions), as opposed to the exchanges in the majority of commercial listening materials, which may sound quite artificial. Finally, the movies present the cultural context of the conversations (Herron et al, 2002; Chapple and Curtis, 2000), hence enhancing more appropriate use of language and preventing cross-cultural misunderstandings. Further, they can be a useful "springboard" (Toplin, 2002) to investigate the target culture.

These advantageous aspects of movies as listening materials provide sufficientiy strong ground for language educators to have them shown in EFL instructions. Although presenting full-length movies in a classroom invites objections mainly due to the time constraint (Bluestone, 2000), after repeated practice I am confident in maintaining that this does not necessarily become a significant obstacle. In tertiary institutions where I have implemented this teaching technique, one session of listening lesson lasts for 100 minutes. Given this condition, apparently showing one entire movie (approximately 90-115 minutes long) and doing the relevant exercises cannot be completed in a single session, but this can be easily overcome by splitting the presentation into two sessions. As a matter of fact, such a division of time can cater for invaluable opportunities for the learners to exercise their power of imagination if we-the learning facilitators - are imaginative in assisting the learners to construct knowledge from the aural perception.

The movie can be presented in two modes: with or without subtitles. The decision to include the subtitles or otherwise in a movie presentation relies on the complexity level of the story and the nature of speech. If the theme and the plot appear to be too complicated to apprehend (for example, Dead Poets Society), it is a wise choice to show the subtitles as this will save the learners from an arduous task, i.e. concentrating on the theme while at the same time grappling with the language. In addition to the complexity of the content, several attributes of the utterances also determines the results of such a decision, for instance, the density of the language and the rate and accent of delivery. Characters who articulate excessively unfamiliar technical terms (such as legal jargons in Music Box), words with a particular accent ( $A$ Walk in Clouds), or fast speech (Next Stop Wonderland) can possibly hamper the learner's efforts to comprehend, so I prefer to provide subtitles in their first language when such movies are on display.
To guide them in comprehending ideas from the oral input as well as strengthening their imaginative faculty, I devise a handout to accompany the movie viewing. This handout comprises three parts and reflects the stages that they undergo during the lessons: previewing, while-viewing, and postviewing (Allan, 1984; Underwood, 1989). A description of each stage will be elaborated below.

\section{Previewing}

It is a common practice in instructions on language decoding (including listening) that at this beginning stage the teacher spends a sufficient amount of time helping the learners build the appropriate schemata to facilitate comprehension (van Duzer, 1997). This conceptually-driven style of teaching are believed to enable the learners to provide a 'hook' that relates the knowledge they already possess and the one to be acquired, making the acquisition occur more smoothly.

Generally the previewing stage consists of two activities, namely, introducing the theme of the movie and preteaching the key vocabulary (Allan, 1985; Tomalin, 1986; Sheerin, 1982). Additionally, some teachers believe it might be quite fruitful to familiarize the learners with the main characters of the movie prior to viewing. Although Chung and Huang (1998) found that preteaching the vocabulary is a better form of advance organizer than the description of the main characters, based on my personal experience in listening classes the latter proves to be helpful in assisting the students' comprehension. Working within this framework, at the beginning of the session briefly describe the theme that underlies the whole plot of the movie, and also the presence or the absence of subtitles in the mother tongue.

Afterwards, I administer a worksheet and an answer sheet, and have the learners scan the items in the worksheet for a few a minutes to familiarize themselves with the learning activities to be carried out before, during and after viewing the movie. If the film is presented with subtitles, before watching it the learners need to read the brief description of the theme and the main characters (Figure 1). Usually the activity of guessing word meaning is not included here because lexical items will be a part of the while-viewing. 


\section{Part l: Before watching}

You are going to watch an interesting movie about Erin and Alan, two strangers who crossed paths several times without realizing each other's presence. Although destiny seemed to push them further and further apart, it had something nice for Erin and Alan.

Now familiarize yourselves with the following characters to help you comprehend the movie.

1. Erin : a nurse, who dropped out of Harvard medical
school. : a student of marine biology, volunteering in the
2. Alan : aquarium.
3. Ander : a musicologist from Brazil.
4. Julie : Alan's classmate.
5. Sean : an activist, Erin's former boyfriend.
6. Piper : Erin's mother, who is eager to find a partner for her daughter.

\section{Figure 1. Previewing Items of Worksheet for Next Stop Wonderland}

However, if the subtitles are absent, in addition to describing the theme I review a number of keywords from the movie to cater for a scaffold that will assist them in the comprehension later (Figure 2). Otherwise, the learners need to expend extra effort to understand what is happening in the movie and may give up disheartened if they fail to do so.

Rather than simply telling them the meaning of these keywords, I prefer presenting them in sentential context and asking the students to perform intelligent guessing to figure out the meaning of each on the basis of the context. Retention is expected to be better if they construct and discover the meaning themselves.

\section{Part I: Before watching}

You are going to watch a movie about Ferris, a high school student who took one last day off before graduating. It also portrays how he cleverly spent it and how it eventually changed his friends' and his own life in the end.

Now quess the meaning of the words/phrases below, using the context as a clue.

1. When his sister broke his favorite ashtray, he went berserk.

2. This is my father's daytime number. You could call him in his office by dialing this number.

3. The downtown area is always busy because there are a lot of shops and offices there.

\section{Figure 2. Previewing Items of Worksheet for Ferris Bueller's Day Off}

The students are supposed to do the vocabulary building exercise orally. I ask them to brainstorm the meaning, giving them a chance to express the inferred synonym or explain the definition to the rest of the class. It is the learners who construct the meaning, and my role in this activity is merely to provide feedback on the accuracy of their inference.

\section{While-viewing}

Immediately after the previewing stage, I engage them in the core activ. ity: viewing the movie. While doing so, they are supposed to answer some items in the worksheet in written form. Again, the presence of subtitles in the film determines the types of questions to ask in the worksheet. If the film is shown with subtitles in the mother tongue, I ask them some questions to check their comprehension and also some others to improve their lexica knowledge. A sample of worksheet items for the movie Next Stop Wonderland to exemplify these two types of questions can be found in Figure 3. 


Part II: While Watching
A. VOCABULARY
In the restaurant
1. What are the English expressions for these:
a. Menawarkan tumpangan
b. Kalau hilang, ya sudah
In Kevin's room
2. What expression did Kevin use to ask his friend to speak with lower
voice?
In the aquarium
3. Frank asked Allen to e__ the fish.
B. COMPREHENSION
1. What was the relationship between Lewis Castleton, the writer of "Heart
Needs Home", and Erin?
2. Why did Erin often point to words in books randomly?

Figure 3. While-viewing Items of Worksheet for Next Stop Wonderland

If the subtitles in the first language are not shown, the items usually in clude comprehension questions only, as illustrated in the excerpt of worksheet for the movie Ferris Bueller's Day Off in Figure 4.

\section{Part II: While Watching}

At home

1. Why did Ferris call Cameron that morning?

2. What were the tips given by Ferris's father over the phone?

- Take a

- Wrap a on his head.

- Get a

At school

3. What did the school's nurse tell Sloane?

\section{Figure 4. While-viewing Items of Worksheet for Ferris Bueller's Day Off}

Each item consists of a brief description of the scene to refer to (written in italics) and one or more questions to be answered. The description of the scene assists the learners to direct their attention to a particular spot in the movie which is related to the question(s) being asked. For instance, the label of 'in the restaurant' above item number 1 in the worksheet for Next Stop Wonderland prompts the students to become more alert when they see the scene of a restaurant on the screen and know immediately what specific information to look for, i.e. the English translation of menawarkan tumpangan (offer a ride) and kalau hilang, ya sudah (Lost is lost). Such an item is intended to increase their vocabulary size by encouraging them to match the Indonesian subtitles with what the film character utters in English.

The comprehension questions are written in similar fashion-questions preceded by a clue of the scene-unless the questions need to be answered by grasping the ideas and/or inferring the answers from the entire movie. In the latter case, the description of the scene is occasionally not required.

In spite of the slight difference in the content of questions for the films with and without subtitles, they are presented in approximately the same way. The following describe the complete activities to be done during the viewing stage. First, allow the students one minute or two for a quick review of the scenes and the questions written in the worksheet, so that they have an idea of the scenes to watch in the entire movie and can focus their attention on the information to seek. Next, play the movie, and after each scene mentioned in the worksheet pause for 15 to 60 seconds, depending on the length 
of the required answer. During this pause, have them supply a correct, brief answer. Occasionally, after viewing a scene once the students still find it quite difficult to recognize the words spoken by the characters or understand their exchange, and request a repetition of that particular scene. In dealing with such a situation, I should emphasize that this exercise aims at enabling and guiding them to comprehend and construct meaning from utterances in the target language, rather than testing their listening ability. As a consequence, they deserve a second chance to view the scene in order to promote better comprehension.

I have mentioned earlier in this paper that due to time constraint a particular film has to be presented in two sessions, and this split turns out to be an advantageous point in the lesson rather than otherwise as it caters for an opportunity of stimulating the learners' imaginative capability. I always finish the first session by stopping the tape or the disc when the story in the movie seemingly gets bleak and unpromising, then have the learners predict how the story will end. To illustrate, I press the 'stop' button of the video player in the following scenes:

- Ferris Bueller's Day Off: after Cameron Fry crashes his father's car out of the garage and severely damages it.

- A Walk in the Clouds: after Victoria Aragon turns the bedroom light on and Paul Sutton watches the light from a distance in the vineyard.

- Chocolat: after Anouk accidentally drops the container made of clay, and begs for an apology from Vianne, agreeing to leave.

- Music Box: after Ann Talbot discovers the old pictures hidden in the music box.

They should write their predictions briefly (usually not more than 5 sentences) on the answer sheet. To do so, they invariably exercise their imaginative power to figure out what events will be likely to occur ahead at the end of the movie based on the existing clues. It is definitely an interesting experience for me to find how remotely different one prediction from another can be. It even takes me by surprise to learn that some of my students' predictions often resemble the unexpected twist in the movie's ending.

This activity involving imagination closes the first session. In the next listening session (usually the following week), I play the rest of the tape/disc and have them continue answering the rest of the items.

\section{Postviewing}

Upon completing the while-viewing activities, they proceed to the postviewing ones. By this time they have already seen the end of the movie and can verify the written result of their prediction against the actual ending. Despite differences that may come up between these two, all of the students' work must be appreciated. The exact or approximate match between what the learners have guessed and what actually occurs in the movie does not matter much. It is the process of arriving at the predicted ending which should be acknowledged.

After reviewing the results of the prediction briefly, the learners are engaged in the next postviewing activity, namely, examining the diversity across cultures, which could be done in two alternatives. One way to accomplish this is to have the learners identify how the target culture in the film differs significantly from their own culture. The inclusion of their home culture is essential as the awareness that they are members of a certain culture assists them in recognizing the "values, expectations, behaviors, traditions, customs, rituals, forms of greeting, cultural signs, and identity symbols", (Straub, 1999) in their surroundings. Such awareness can lead them to interpret the same aspects of other cultures more objectively. To facilitate the students' attempt to contrast the cultures, I usually devise a table that can help them spot the distinct aspects of both. Figure 5 is an example of such an item taken from the worksheet for Ferris Bueller's Day Off. 


\begin{tabular}{|l|}
\hline Part III: After Watching \\
You have seen some activities or events that reflect the American culture in \\
the movie, and they are quite different in Indonesia. In the left column, list \\
these typically American activities or events. In the right column, write the \\
equal ones in Indonesia.
\end{tabular}

Figure 5. Postviewing Item of the Worksheet for Ferris Bueller's Day Off

This item is designed to allow the learners to contrast the American culture - where all the acts and events in the movie take place-and the Indonesian culture in which they have lived and been raised. The results indicate that most of them can accurately describe how dissimilar the two cultures view parent-children relationship, teacher-students relationship, friendship, and other social issues.

Another method of examining diversity across cultures is making use of the cultural issues depicted in the films. If the film happens to be rich of cross-cultural materials to dig up, such as $A$ Walk in the Clouds where the Mexican culture encounters the American one, I construct an item that directs the learners to delve into the distinct manners in which two cultures treat the same issue in the movie (Figure 6).

\section{Part III: After watching}

Paul who came from Maligne (Illinois) had difficulties in adjusting to the life of the Arragons who were of Mexican origin and lived in Napa (California). List a few things which Paul viewed differently from the Arragons, and therefore caused cross-cultural misunderstanding.

\begin{tabular}{|l|l|}
\hline Paul & The Arragons \\
\hline & \\
\hline & \\
\hline
\end{tabular}

\section{Figure 6. Postviewing Item of the Worksheet for $A$ Walk in the Clouds}

Schroeder (2004) points out the great linguistic diversity that exists in the U.S.A. and results from the influence of different cultures there. This serves as a reminder that cultural diversity is existent not only between one country and another, but within a single country as well. EFL learners need to have knowledge on this to prevent misperception that the English nativespeakers live in a community who shares a uniform culture in different parts of one particular country.

It is strongly recommended that this activity of contrasting be followed by an assertion from the teacher that cultures simply differ and none is superior to the others. This is especially vital as some learners may tend to hold an inaccurate opinion that their own culture is "right" and "full of politeness", whereas the others are "wrong" and "full of unacceptable values". They should be made aware that diversity among cultures must be highly valued and respected, and such appreciation and unprejudiced attitude are extremely beneficial when they are learning a foreign language as language is inseparable from the culture where it is spoken. 


\section{CONCLUSION}

Movies turn out to be an effective teaching device to develop the EFL learners' listening skills and equip them with the relevant knowledge of the target culture simultaneously. Their capacity to arouse the learners' motivation and their potential to engage the learners in a variety of fruitful activities related to aural perception in the target language can scarcely be denied. After class, my students often personally express their great interest in the movies I have selected for them and the ways they are exploited to improve listening skills. Additionally, many of them report the benefits they attain from making unrestrained efforts to predict how a particular movie ends. They admit their curiosity keeps high while waiting for the subsequent session in the following week, and-when they finally do watch the endingfeel amused irrespective of the relevance between the predicted and the actual ending. They also emphasize the usefulness of cultural experience they undergo by viewing the movies. Obviously the activities of contrasting the diversity across cultures can raise their awareness of the existence of such a phenomenon and sensitize them, so that they can use the language in the proper cultural context. On the whole, I have received encouraging feedbacks from the learners and therefore suggest that movies be utilized in the teaching of EFL listening because of their pedagogical merits.

\section{REFERENCES (BOOKS AND PAPERS)}

Allan, M. 1985. Teaching English with Video. Essex: Longman.

Bluestone, C. 2000. Feature Film as a Teaching Tool. College Teaching $48(4), 141-146$

Byram, M., \& Grundy, P. 2002. Introduction: Context and Culture in Language Teaching and Learning. Language, Culture and Curriculum, 15(3), 193-195.

Chapple, L., \& Curtis, A. 2000. Content-based Instruction in Hong Kong: Student Responses to Film. System, 28, 419-433.

Chung, J. M., \& Huang, S. C. 1998. The Effects of Three Aural Advance Organizers for Video Viewing in a Foreign Language Classroom. System, 26, 553-565.

Eken, K. 2003. 'You've Got Mail': A Film Workshop. ELT Journal, 57(1), 51-59.
Herron, C., Dubreil, S., Corrie, C., \& Cole, S. P. 2002. A Classroom Investigation: Can Video Improve Intermediate-Level French Language Students' Ability to Learn about a Foreign Culture? The Modern Language Journal, 86(1), 36-53.

Herschenhorn, S. 1979. Teaching Listening Comprehension Using Live Language. In M. Celce-Murcia \& L. McIntosh (Eds.), Teaching English as a Second or Foreign Language (pp. 65-73). Rowley: Newbury House Publishers, Inc.

Lessard-Clouston, M. 1997. Towards an Understanding of Culture in L2/FL Education. The Internet TESL Journal, 3(5).

Lonergan, J. 1984. Video in Language Teaching. Cambridge: Cambridge University Press.

Matikainen, T., \& Duffy, C. B. 2000. Developing Cultural Understanding. Forum, 38(3), 40.

Nunan, D. 1998. Approaches to Teaching Listening in the Language Classroom. Paper presented at the Korea TESOL Conference, Seoul.

Pryor, A. 2004. Deep Ethnography: Culture at the Core of Curriculum. Language Arts, 81(5), 396-405.

Schroeder, W. 2004. Do You Speak American? Humanities, 25(2), 10-14.

Sheerin, S. 1982. Exploiting Television Videos with Particular Reference to Teaching ESP. In M. Geddes \& G. Sturtridge (Eds.), Video in Language Classroom (pp. 122-133). London: Heinemann Educational Books Ltd.

Sommer, P. 2001. Using Film in the English Classroom: Why and How? Journal of Adolescent and Adult Literacy, 44(5), 485-487.

Stempleski, S. 1992. Teaching Communication Skills with Authentic Video. In S. Stempleski \& P. Arcario (Eds.), Video in Second Language Teaching: Using, Selecting and Producing Video for the Classroom (pp. 7 24). Alexandria: Teachers of English to Speakers of Other Languages, Inc.

Straub, H. 1999. Designing a Cross-Cultural Course. Forum, 37(3), 2.

Telatnik, M. A., \& Kruse, W. D. 1982. Cultural Videotapes for the ESL Classroom. In M. Geddes \& G. Sturtridge (Eds.), Video in Language Classroom (pp. 171-181). London: Heinemann Educational Books, Inc.

Tomalin, B. 1986. Video, Radio \& TV in the English Class. London: Macmillan Publishers.

Toplin, R. B. 2002. Invigorating History: Using Film in the Classroom. Magazine of History, 16(4), 5-6. 
Underwood, M. 1989. Teaching Listening. New York: Longman.

Van Duzer, C. 1997. Improving ESL Learners' Listening Skills: At the Workplace and Beyond. Washington D.C.: National Clearinghouse for ESL Literacy Education.

\section{REFERENCES (VIDEOS)}

Anderson, B. 1998. Next Stop Wonderland. U.S.A: Miramax. Arau, A. 1995. A Walk in the Clouds. U.S.A.: 20th Century Fox. Costa-Gravas 1989. Music Box. U.S.A.: Carolco.

Hallstrom, L. 2000. Chocolat. U.K/U.S.A.: Miramax.

Hughes, J. 1986. Ferris Bueller's Day Off. U.S.A.: Paramount.

Weir, P. 1989. Dead Poets Society. U.S.A.: Touchstone. 